\title{
PELATIHAN MANAJEMEN KARIR SERTA ETIKA BEKERJA UNTUK MENGEMBANGKAN KEPRIBADIAN DAN MOTIVASI MAHASISWASTIKES BHAKTIALQODIRI JEMBER
}

\author{
Vera Firdaus \\ FIP, IKIP PGRI JEMBER \\ Email: verafirdaus06@gmail.com
}

\begin{abstract}
Personality is one of the dominant factors that determine the attitudes and behavior of humans in order to arrange how to relate to others, work together effectively. Career management means for people to be able to plan his careers to improve his status and salary, ensuring the safety of jobs, and retain his competitive value in the labor market. In order to enter the world of work, the students also need to recognize the strategic function of himself, intelligent and has a competitive value. This strategic function must be framed with ethics, personality and devotion. This training is intended to make students of Nursing and Midwifery Academy of Health (STIKES) Bhakti Al Qodiri Jember have a positive mindset about the direction of his career with organizing themselves, arrange the way of thinking and doing management career. The results of the training program is increasing knowledge and understanding of students about career management and ethics work, the students are able to measure his motivation. Appreciation and enthusiasm for the process of ongoing activities, student involvement in the game, as well the interesting dialogue and as the desire for sustainable activity is a measure of the success of this training program. This program is also to establish good cooperation between STIKES Bhakti Al Qodiri and IKIP PGRI Jember which is signed in a Memorandum of Understanding.
\end{abstract}

Keywords: Career management, ethics work, personality,motivation

\begin{abstract}
Abstrak. Kepribadian merupakan salah satu faktor dominan yang menentukan sikap dan perilaku manusia agar dapat mengatur bagaimana berhubungan dengan orang lain, bekerja sama secara efektif. Manajemen karir dimaksudkan agar individu mampu merencanakan karir sehingga mampu meningkatkan status dan gaji, memastikan keselamatan pekerjaan, dan mempertahan nilai kompetitif dirinya di pasar tenaga kerja. Dalam rangka memasuki dunia kerja, mahasiswa juga perlu mengenali fungsi strategis dirinya, yang cerdas dan memiliki nilai kompetitif. Fungsi strategis ini haruslah dibingkai dengan etika, kepribadian serta ketaqwaan. Pelatihan ini dimaksudkan agar mahasiswa Keperawatan dan Kebidanan Akademi Kesehatan (Stikes) Bhakti Al Qodiri Jember mempunyai mindset positif tentang arah karirnya dengan menata diri, menata cara berfikir dan melakukan manajemen karirnya. Hasil yang diperoleh dari program pelatihan adalah meningkatnya pengetahuan dan pemahaman mahasiswa tentang manajemen karit dan etika bekerja, mahasiswa mampu mengukur motivasi dirinya. Mahasiwa di Akademi Kesehatan (Stikes) Bhakti Al Qodiri Jember sangat apresiatif terhadap pelaksanaan kegiatan pengabdian kepada masyakarat ini. Ini tampak pada antusiasme selama proses kegiatan berlangsung, keterlibatan mahasiswa dalam permainan ini. Serta dialog yang berlangsung sangat menarik. Program ini juga mampu menjalin kerja sama baik antara Stikes Bhakti Al Qodiri Jember dengan IKIP PGRI Jember yang ditandai dengan nota kesepakatan bersama.
\end{abstract}

Kata Kunci: Manajemen karir, etika bekerja, kepribadian, motivasi 


\section{PENDAHULUAN}

Perguruan Tinggi atau institusi umumnya memiliki wadah yang bisa digunakan mahasiswa sebagai ajang melatih serta mengembangkan dirinya. Kegiatan pelatihan, seminar, praktikum di kampus dan di luar kampus maupun unit kegiatan mahasiswa merupakan sebagian contoh dari upaya perguruan tinggi mengembangkan kepribadian dan potensi mahasiswa, melatih kecakapan berorganisasi, melatih diri menghadapi berbagai masalah, belajar menyampaikan gagasan, serta bersosialisasi.

Perguruan tinggi berkualitas akan mampu mentransformasikan satuan pendidikan yang bermutu kepada mahasiswa sehingga nampak perubahan aspek berfikir, kognitif, perilaku maupun konatif. Hal ini dikemukakan Firdaus (2015:329), The quality of education is very dependent on the capacity of the education unit in changing the student to get a change, that change-related aspects of thinking, cognitive, behavioral and connative.

Menururt Alwi (2008:55) berpendapat bahwa pelatihan merupakan salah satualternatif untuk membangun kompetensi individu, karena dalam pelatihan akan diperoleh pengetahuan conceptual, tehnical, dan human skill cara berfikir. Sedangkan mengubah cara berfikir tidak hanya melalui pelatihan saja, melainkan perlu dengan pemahaman individu akan nilainilai etika.

Mahasiswa diharapkan mampu mengendalikan dan mengelola diri sendiri, bekerja dengan lebih baik, serta mampu berinteraksi dengan orang lain. Dalam persiapannya memasuki dunia kerja, maka mahasiswa perlu belajar manajemen diri, belajar dan bisa menerapkan etika bekerja baik saat praktikum, perkuliahan, maupun dalam aktivtas sehari-hari. Karena sejatinya Etika bekerja berkaitan erat dengan aktiivitas kehidupan manusia, yang mengatur sikap, perilaku di dalam lingkungan kerja.

Dengan latar belakang pendidikannya, mahasiswa diharapkan memiliki visi untuk menyiapkan arah masa depan dengan upaya mempersiapkan karir melalui jenjang perguruan tinggi. Sebagai ujung tombak kemajuan bangsa, mahasiswa memiliki tanggung jawab untuk mengembangkan potensi diri dengan meningkatkan kompetensi diri. Fungsi strategis mahasiswa sebagai sumber daya manusiayang cerdas dan kompetitif haruslah dibingkai dengan etika, kepribadian serta ketaqwaan.

Menurut Ulrich bahwa seseorang yang memiliki keunggulan kompetitif akan memiliki share mindset yaitu cara berfikir yang rasional mengenai tujuan dan cara mencapainya(dalam Alwi,2008:50). Sedangkan Pieter dan Lubis (2010:186) mengemukakan bahwa di masa usia dewasa awal (21-35 tahun) sekolah atau pendidikan dianggap sebagai dasar untuk meraih keberhasilan sosialnya, karier dan kepuasan kerja, dan hal inilah yang kemudian menjadi stimulasi bagi motivasi baginya untuk bekerja.

Mahasiswa Keperawatan dan Kebidanan haruslah memiliki mindset tentang arah karirnya dengan menata diri, menata cara berfikir dan melakukan manajemen karirnya sedari awal agar motivasi dan tujuan hidupnya lebih terarah. Menurut Winkel dan Hastuti (2006:625) orang muda haruslah mendapatkan bekal pelatihan teknis tambahan serta bekal pendidikan formal agar berhasil memasuki jabatan yang diinginkannya.

Menurut Pieter dan Lubis (2010:1), sangat penting bagi mahasiswa sebagai pelaku dalam dunia medis mendapatkan pengetahuan dan pemahaman akan pembentukan sikap professional. Sebab mahasiswa akan berinteraksi dengan manusia yang lainnya yang kerap kali dalam interaksi tersebut terjadi dalam situasi 
serba darurat, penuh kepanikan, dan kesedihan.

\section{Manajemen Karir}

Kompetisi global serta dinamika perubahan ekonomi di Indonesia menyebabkan seorang mahasiswa atau calon tenaga kerja harus lebih focus dalam menata visi atau tujuan masa depan cita-citanya. Visi tersebut tertuang pada gambaram karir yang diinginkan, langkah-langkah perencanaan karier, serta mengisi kariernya menjadi lebih bermakna. Data International Labour Organization (ILO, 2015:11) di Indonesia pengangguran terbuka menjadi persoalan bagi kalangan muda, dimana angka pengangguran terbuka di kalangan penduduk usia 15 sampai 24 tahun diperkirakan sebesar 22,2\% pada Agustus 2014 dan 18,3\% pada Februari 2015.

Indonesia sebagai negara yang sedang berkembang melakukan beragam upaya guna meningkatkan kualitas sumber daya manusianya. Zainal (2014:45) mengemukakan bahwa percepatan peningkatan mutu sumber daya manusia (human development) ditentukan oleh efektivitas pelaksanaan seperangkat kebijakan pembangunan baik di tingkat daerah, nasional maupun internasional.

Koontz \& Donnel dalam bukunya Principles of Management mengemukakan Management involves getting things done thought and with people. Hal ini mengandung pengertian bahwa manajemen berhubungan dengan pencapaian tujuan yang dilakukan melalui orang-orang lain (dalam Purwoko,2008:6).

Menurut Daft (2008:6) manajemen (management) merupakan pencapaian tujuan organisasi agar lebih efektif dan efissien melalui perencanaan, pengorganisasian, pengarahan serta pengendalian sumber daya organisasi. Sedangkan karier menurut Simamora (2006: 412) merupakan urut-urutan posisi yang diduduki oleh seseorang selama hidupnya.
Karier juga merupakan perubahan nilainilai, sikap dan motivasi yang terjadi karena seseorang menjadi semakin tua.

Melihat besarnya peluang dan besarnya tenaga kerja yang diperlukan agar peran manajemen dapat efektif dan efisienuntuk menjawab peluang dan tantangan, maka dibutuhkan menetapkan strategi yang kompetitif, evaluasi dengan cermat serta perencanaan yang matang. Perencanaan Karir oleh individu menurut Simamora (2006:420) meliputi:

1. Penilaian diri untuk menentukan kekuatan, kelemahan, tujuan, aspirasi, kebutuhan, ataupun jangkar karirnya

2. Penilaian pasar tenaga kerja dalam menentukan kesempatan yang tersedia baik di dalam maupun di luar organisasi

3. Penyusunan tujuan karir yang dievaluasi

4. Pencocokan kesempatan terhadap kebutuhan, tujuan, pengembangan strategi karir

5. Perencanaan strategi karir

\section{Etika Bekerja}

Etika bekerja mengatur sikap, perilaku di dalam lingkungan kerja. Hal ini menyangkut hubungan antara karyawan dengan atasan, sesama rekan kerja Robbins dan Counter (2009:134) mendefinisikan etika sebagai prinsip, nilai dan kepercayaan yang dimaksudkan untuk memberi keputusan apakahn tindakan tersebut benar ataukah salah. Etika sering sekali dicerminkan sebagai kualitas kepribadian seseorang. Aspek etika kerja terdiri dari:

1. Interpersonal skills, temasuk didalamnya adalah kebiasaan, sikap, tingkah laku, penampilan.

2. Perkembangan interpersonal skills dipengaruhi pengalamannya yang berhubungan dengan interaksi individu dengan keluarga, teman, dan proses belajar kita dalam mengamati dan berhubungan dengan dunia sekitar. 
3. Interpersonal Skills mempengaruhi kesempatan serta kesuksesan individu sehingga merupakan tanggung jawab masing-masing pribadi.

4. Inisiatif dan dapat diandalkan.

\section{Mengembangkan Kepribadian}

Pengertian kepribadian menurut G.W. Allport adalah pola perilaku dan proses mental yang unik yang menentukan sifat individu serta interaksinya dengan lingkungan (dalam Koswara 1991:11). Sedangkan Atkinson (1983;133) mengartikan kepribadian sebagai pola perilaku dan cara berfikir yang khas, yang menentukan penyesuaian diri seseorang terhadap lingkungan.

Kualitas kepribadian individu diawali dibentuk oleh perilakuyang bila dilakukan terus menerus akan menjadi sebuah kebiasaan dan dari kebiasaan akan membentuk sikap. Penguatan (Reinforcement) terhadap sikap akan membentuk karakter. Menurut Allport (dalam Suryabrata 1993:360), kepribadian masa dewasa memiliki karakteristik:

1. Extention Of Self. Seseorang yang ingin menikmati beragam kegiatan, namun memiliki proyeksi ke masa depan dengan merencanakan dan mengharapkan (planning, hoping).

2. Self Objectification. Ada dua komponen dalam hal ini yaitu (a) Insight, ialah kecakapan individu memahami dirinya. (2) Humor, yaitu kemampuan mempertahankan hubungan positif dengan dirinya sendiri dan obyek-obyek yang disenangi.

3. Philosophy Of Life. Individu memang harus dapat berfikir obyektif, akan tetapi pasti ada latar belakang yang menjadi alasan sesuatu yang dilakukan atau dikerjakannya.

\section{Cara Mengembangkan Kepribadian Dan Potensi Diri}

1. Banyak bersyukur dan berhenti mengeluh

2. Kenali Potensi Diri (Kenali Kelebihan, kelemahan, hobi, bakat, minat

3. Konsisten pada cita-cita, Jangan mudah menyerah

4. Bangkitkan motivasi diri dengan mengenal tujuan meraih cita-cita

5. Menetapkan tujuan, Cita-cita, target yang ingin dicapai

6. Jangan sia-siakan waktu hanya untuk melamun, galau dan menunggu. Buatlah dirimu menjadi orang yang bermanfaat bagi orang lain.

\section{Motivasi Bekerja}

Motivasi menurut Robbins (2002:55) adalah keinginan melakukan, sebagai Alwidikondisikan oleh kemampuan upaya itu guna memenuhi suatu kebutuhan individual. Motivasi/dorongan untuk berprestasi dan memberikan yang terbaik dari dirinya berkaitan erat dengan antuasiasme/semangat dalam merespon pembelajaran.

Bekerja memiliki arti melaksanakan suatu tugas yang diakhiri dengan sebuah karya yang bisa dinikmati oleh manusia yang bersangkutan. Berikut faktor intrinsik (yang bersumber dari dalam diri seseorang) yang disebut sebagai satisfer motivation :

1. Prestasi yang ingin diraih (achievement)

2. Pengakuan orang lain(Recognition)

3. Tanggung jawab (Responsibility)

4. Peluang untuk maju (Advancement)

5. Kepuasan pada kerja itu sendiri (the work it self)

6. Kemungkinan pengembangan karir (The Possibility Of Growth) 


\section{Cara Membangkitkan Dan Memperkuat Motif}

Menurut Yusuf dan Nurihsan (2008:164) terdapat beberapa usaha untuk membangkitkan dan memperkuat motif, antara lain:

1. Menciptakan situasi kompetisi yang sehat

2. Adakan pacemaking

3. Informasikan tujuan yang jelas

4. Memberikan ganjaran (reward)

5. Memberikan kesempatan untuk sukses

Bagaimanakah meletakkan harapan akan keberhasilan?

1. Membangkitkan motivasi dari dalam diri

2. Menekankan pada diri pentingnya pendidikan bagi kehidupan sehari-hari

3. Menekankan pentingnya kerja keras

Barbara Prashnig (2007:236) dalam bukunya The Power Of Learning Styles, mengutip pendapat Sternberg tentang orang-orang cerdas yang sukses, antara lain :

1. Memotivasi diri sendiri dan belajar mengendalikan gerak hati mereka

2. Menerjemahkan pikiran ke dalam tindakan dan tahu kapan harus bersikap gigih

3. Suka mengambil inisiatif dan tahu bagaimana memanfaatkan yang terbaik dari kemampuan mereka

4. Memiliki orientasi produk dan tidak takut dengan risiko kegagalan

5. Tidak suka menunda, langsung menyelesaikan tugas dan menindaklanjutinya

6. Bersikap luwes dan mau menerima kesalahan secara adil

7. Mandiri dan mampu menunda kepuasan

8. Mampu melihat rimba dan pepohonannya

9. Mencari cara untuk mengatasi kesulitan pribadi \& menolak mengasihani diri sendiri

10. Berfokus untuk meraih tujuan

11. Memiliki cukup rasa percaya diri dan keyakinan akan kemampuan diri dalam meraih tujuan
12. Menyeimbangkan antara pemikiran analitis, kreatif dan praktis

\section{Tujuan dan Kegunaan Pelatihan}

1. Untuk memberikan pengertian kepada mahasiswa tentang manajemen karir

2. Memberikan bekal dan pemahaman kepada mahasiswa mengenai etika bekerja

3. Memberikan motivasi untuk mengembangkan kepribadian

4. Memberikan pemahaman pentingnya memperkuat motivasi diri

5. Memberikan pemahaman tentang pentingnya semangat/antusiasme dalam menggapai keberhasilan

\section{Manfaat Pelatihan}

1. Diharapkan kegiatan pembekalan ini mampuu mengubah paradigma mahasiswa menjadi lebih optimis dalam menata masa depannya

2. Memberikan masukan kepada mahasiswa agar senantiasa bangkit manakala menghadapi stres dan tidak berputus asa

3. Memberikan masukan tentang cara membangun dan memperkuat motivasi, agar lebih konsisten pada pilihan karir yang akan ditempuh nantinya

4. Memberikan gambaran agar lebih mencintai profesi atau pekerjaannya

\section{Target Pelatihan}

1. Pelatihan ini dimaksudkan untuk memberikan pengetahuan mahasiswa keperawatan dan kebidanan tentang manajemen karir yang meliputi perencanaaan, tahapan karir.

2. Peningkatan pemahaman mahasiswa pentingnya memiliki etika bekerja

3. Melalui pelatihan ini mahasiswa akan memotivasi diri dalam belajar dan mampu 
memperkuat motivasinya untuk menata masa depannya

\section{Luaran Kegiatan Pelatihan}

Target luaran kegiatan ini adalah publikasi ilmiah dalam jurnal pengabdian masyarakat tahun 2017, yang mengkaji tentang pelatihan manajemen karir serta etika bekerja untuk mengembangkan kepribadian dan motivasi mahasiswa Stikes Bhakti Al Qodiri Jember.

\section{METODE PELAKSANAAN}

Metode penyampaian. Metode kegiatan dan metode penyampaian kegiatan adalah dengan metode ceramah, tanya jawab / dialog, pemutaran video, Role play/Game dengan mahasiswa baru di Akademi Kesehatan (Stikes)
Bhakti Al Qodiri Jember untuk memberikan pembekalan dan motivasi.

Metode evaluasi yang akan dilaksanakan meliputi: mengidentifikasi faktor pendukung dan penghambat selama pelaksanaan serta mengklasifikasi permasalahan yang didiskusikan peserta.

\section{Tempat dan Waktu}

Pelaksanaan kegiatan dilakukan dalam rangka pembekalan Ospek mahasiswa di Gedung Stikes Bhakti Al Qodiri Jember, pada hari Rabu tanggal 31 Agustus 2016. Pemberian materi ini diberikan oleh ibu Vera Firdaus, S.Psi., MM. Kegiatan dilaksanakan selama satu hari dengan rincian pelaksanaan kegiatan seperti yang tersaji pada tabel di bawah ini :

Tabel 1. Jadwal Pelaksanaan Kegiatan

\begin{tabular}{lll}
\hline \multicolumn{1}{c}{ Kegiatan } & \multicolumn{1}{c}{ Deskripsi Kegiatan } & \multicolumn{1}{c}{ Waktu } \\
\hline Pembukaan & Pembacaan curriculum vitae penyaji & $12.30-12.40$ \\
\hline \multirow{2}{*}{ Pembekalan } & $\begin{array}{l}\text { Presentasi Materi Tentang Manajemen Karir dan } \\
\text { Etika Bekerja }\end{array}$ & $12.40-13.00$ \\
\hline \multirow{2}{*}{ Questionnaire Motivasi Belajar } & $\begin{array}{l}\text { Angket Motivasi Belajar: "Bagaimana Perasaan } \\
\text { Anda Terhadap Pelajaran" }\end{array}$ & $13.30-14.00$ \\
\hline Pembekalan & Presentasi dan Pemutaran Video Motivasi & $14.00-14.30$ \\
\hline Role Play & Mengembangkan kepribadian & $14.30-15.00$ \\
\hline & Diskusi & $15.00-15.30$ \\
\hline
\end{tabular}

\section{Khalayak Sasaran}

Pelaksanaan pengabdian masyarakat dilaksanakan dengan memberikan pembekalan kepada mahasiswa baru serta senat mahasiswa sebagai panitia ospek Stikes Bhakti Al Qodiri Jember. Khalayak sasaran adalah mahasiswa berusia 18-22 tahun atau dalam fase dewasa awal.

\section{HASIL DAN PEMBAHASAN}

Data hasil kegiatan pengabdian kepada masyarakat ini berupa data deskriptif yaitu data berupa gambaran secara tertulis yang dapat diamati. Data yang telah diperoleh dianalisis dan disajikan dalam bentuk narasi.Berdasarkan wawancara, tanya jawab dan pengamatan langsung selama kegiatan berlangsung, kegiatan pengabdian pada masyarakat ini memberikan hasil sebagai berikut:

\section{Hasil Observasi}

1. Meningkatnya pengetahuan dan pemahaman mahasiswa tentang mengatasi stres dan frustasi yang nampak pada antusiasme mengkuti presentasi dan pemutaran video

2. Mahasiswa mampu mengukur motivasi diri dalam mengikuti pembelajaran, sebagian bahan untuk mengevaluasi, membangun 
dan memperkuat motivasi

3. Mahasiswa sebagai khalayak sasaran mengikuti keseluruhan rangkaian kegiatan pengabdian masyarakat dengan penuh antusiasme. Hal ini terutama nampak selama presentasi, keterlibatan dalam role play maupun quis, serta dialog yang berlangsung.

\section{Hasil wawancara}

1. Sebagian besar khalayak sasaran mengaku sangat puas mengikuti keseluruhan rangkaian kegiatan pembekalan.

2. Sebagian besar khalayak sasaran mulai

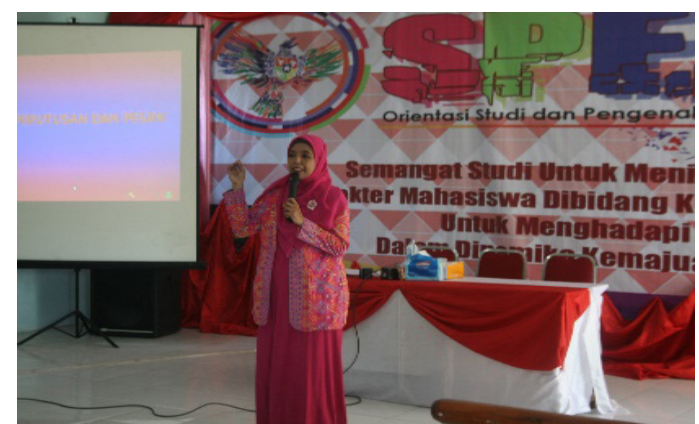

Gambar 1. Kegiatan Pelatihan Stikes Bhakti Al Qodiri Jember

\section{SIMPULAN}

Pelatihan merupakan program yang mentransformasikan pengetahuan agar peserta pelatihan memperoleh pengetahuan conceptual, tehnical, dan human skill cara berfikir. Perguruan Tinggi pada umumnya mempunyai wadah untuk melatih dan mengembangkan potensi mahasiswa, melatih kecakapan berorganisasi, melatih diri menghadapi berbagai masalah, belajar menyampaikan gagasan, serta bersosialisasi. Individu perlu merencanakan karirnya agar dapat meningkatkan status dan gaji, memastikan keselamatan pekerjaan, dan mempertahan nilai kompetitif dirinya. Dengan mengenali dirinya sendiri maka orientasi ke dalam dirinya sendiri akan lebih mudah dilakukan, sehingga mekanisme self management akan berjalan dengan baik. menyadari pentingnya motivasi untuk mengatasi stres dan frustasi.

\section{Tindak Lanjut}

Kegiatan selanjutnya dalam pengabdian pada masyarakat ini dengan menginformasikan kepada orang tua siswa yang lain, dan menjalin komunikasi dengan lembaga di lingkungan Stikes Bhakti Al Qodiri Jember. Kelanjutan kegiatan ini adalah pelaksanaan nota kesepakatan (MOU) dengan menjalin kerja sama baik dengan Laboratorium Bimbingan Konseling IKIP PGRI Jember maupun penelitian bersama dosen Stikes Bhakti Al Qodiri Jember.

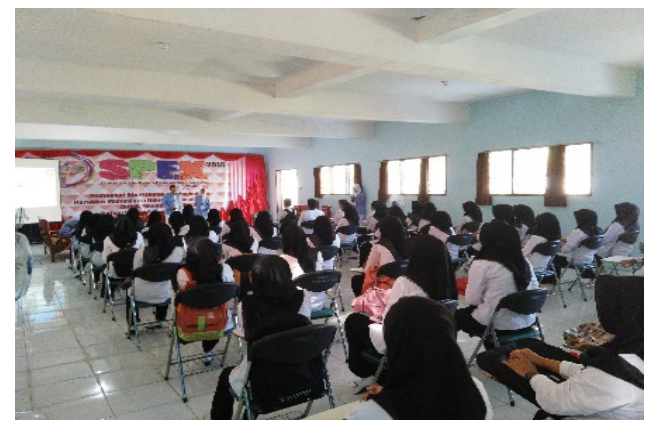

Mahasiswa Keperawatan dan Kebidanan Akademi Kesehatan (Stikes) Bhakti Al Qodiri Jember perlu memiliki mindset tentang arah karirnya dengan menata diri, menata cara berfikir dan melakukan manajemen karirnya sedari awal agar motivasi dan tujuan hidupnya lebih terarah. Metode pelatihan dengan presentasi, tanya jawab / dialog, questionnaire, Role play/ Game pemutaran video.

\section{DAFTAR PUSTAKA}

Alwi, Syafarudin. 2008. Manajemen Sumber Daya Manusia, Strategi Keunggulan Kompetitif. Edisi Kedua. Yogyakarta: BPFE-Yogyakarta.

Atkinson, Rita L. Atkinson Richard C. Hilgard, Ernest R. 1983. Pengantar Psikologi jilid kedua (Edisi VIII), Jakarta: Erlangga. 
Daft, Richard L. 2006. Manajemen. Edisi VI. Buku I. Jakarta: Salemba Empat.

Firdaus, Vera. Cares Program Child Problems: Improvement Efforts Of Empathy And Motivation Altruistic Practicum Management Services Through Guidance And Counseling's Students. Surabaya: Proceeding Seminar Internasional Pendidikan Guru Anak Usia Dini: International Conference Of All Care For Children On Early Childhood Development. ISBN: 978-979-028-742-6.

Hurlock, Elizabeth B.. 1991.Perkembangan Anak (Edisi V) Jakarta: Erlangga.

Kantor Perburuhan Internasional, International Labour Organization (ILO). 2015. Tren ketenagakerjaan dan sosial di Indonesia 2014 - 2015: Memperkuat daya saing dan produktivitas melalui pekerjaan layak. http://www.ilo.org/wcmsp5/groups/ public/---asia/---ro-bangkok/---ilo-jakarta/ documents/publication/wcms_381565. pdf.

Koswara, E. 1991. Teori-Teori Kepribadian, Psikoanalisis, Behaviorisme, Humanistik. Bandung: PT ERESCO.

Pieter, Herri Zan, Lubis, Namora Lumongga. Pengantar Psikologi Untuk Kebidanan, Jakarta: Kencana Prenada Media Group.
2010.

Purwoko, Budi.Organisasi Dan Manajemen Bimbingan Konseling. Surabaya: Unesa University Press. 2008

Prashing, Barbara. 2007.The Power Of Learning Style, Cetakan II. Bandung: Kaifa.

Robbins, Stephen. Coulter, Mary. 2010. Manajemen. Jilid I. disi Kesepuluh. Jakarta: Erlangga.

Suryabrata, Sumadi. 1993. Psikologi Kepribadian. Cetakan Keenam. Jakarta: PT Raja Grafindo Persada.

Simamora, Henry, Manajemen Sumber Daya Manusia (Edisi III), Yogyakarta: Sekolah Tinggi Ilmu Ekonomi YKPN, 2006.

Winkel, Hastuti, Bimbingan \& Konseling Di Institusi Pendidikan, Yogyakarta: Media Abadi, 2006.

Yusuf, Syamsu L.N \& Nurihsan, A. Juntika. 2008. Landasan Bimbingan \& Konseling. Cetakan Ketiga. PT Remaja Rosdakarya, Bandung.

Zainal, Veithzal Rivai., Kamal, Haryadi., Muhammad, Natsir. 2014. The Economics Of Education, Mengelola Pendidikan Secaara Profesional Untuk Meraih Mutu Dengan Pendekatan Bisnis. Jakarta: Gramedia Pustaka Utama. 